\title{
Albas e antilogias da poesia brasileira contemporânea: um ensaio sobre Orides Fontela e Sebastião Uchoa Leite
}

\section{Ricardo Souza de Carvalho}

Resumo: A partir da análise de alguns aspectos da trajetória dos poelas Orides Fontela e Sebastiân Uchoa Leite, à primeira vista alheios a adesōes estritas a movimentos e tendências, pretendemos refletir sobre seus diálogos com a tradição poética e seus legados para a poesia brasileira contemporănea. Palavras-chave: Orides Fontela, Sebastiāo Uchoa Leite, poesia contemporânea.

Abstract: From the analysis of some aspects of the Orides Fontela's and Sebastiāo Uchoa Leite's works, at first glance unrelated to the strict movements and trends, we reflect on its dialogues with the poetic tradition and its legacy for contemporary Brazilian poetry Keywords: Orides Fontela, Sebastiăo Uchoa Leite, contemporary poetry. 
Na década de 80 do século já passado, em mais de um texto crítico, fazia-se um balanço não muito animador da produção poética contemporânea. Na esteira da fértil produção da chamada "poesia marginal" dos anos 1970, denunciada por uma facilidade ou gratuidade, ou ainda na insistência de vertentes mais anteriores, como a poesia concreta, não se via destacar nenhuma grande voz lírica ou grande proposta poética. ${ }^{1}$ Ficava-se com a impressão de que o último grande poeta teria sido João Cabral de Melo Neto, que, aliás, naquele momento publicava suas últimas coletâneas, espécie de fecho de uma época áurea da poesia moderna brasileira que começara nos anos 1920.

Tal diagnóstico, à parte seus acertos ou exageros, pode ser questionado ao se levarem em conta os diferentes tempos históricos em questão. De acordo com Marcos Siscar, no artigo "A cisma da poesia brasileira", muitos dos valores que nortearam o modernismo brasileiro, como o nacionalismo aliado a um projeto modernizador para o país, não são suficientes para explicar os novos poetas. A ausência de um projeto coletivo, antes de ser um traço pejorativo, faria parte de um contexto mais amplo, expressado por diferentes poetas e poéticas. A poesia, nessa direção, dramatizaria certa angústia de busca de sentido. ${ }^{2}$

À luz desse pressuposto, analisar a obra de poetas que produziram ao longo das décadas de 1960 a 1980 pode adquirir maior relevo. Nesse sentido, a produção de poetas como Orides Fontela (1940-1998) e Sebastião Uchoa Leite (1935-2003), que não aderiram totalmente ou ficaram à margem das tensões estéticas e políticas desse período, ganha significação justamente nesse aparente cenário de ausência de parâmetros mais claros. E poetas que, antes de mais nada, na melhor tradição da poesia de vanguarda, experimentam e desafiam a linguagem. Além disso, poetas que fugiam e chegavam a ter pavor de rótulos e classificações.

A paulista Orides Fontela é o exemplo mais expressivo de uma não adesão à multiplicidade de tendências dessas décadas, pois sua própria trajetória foi avessa à grande circulação e publicidade. Somente após o estímulo recebido por críticos como Davi Arrigucci Jr. sua poesia começa a ser mais conhecida, mesmo que ainda em círculos restritos. A edição de sua não muita extensa poesia, reunida em 2006,

1 Consultar, sobretudo, os textos de lumna Maria Simon e Vinicius Dantas, "Poesia ruim, sociedade pior" (Novos Estudos. Sāo Paulo: Cebrap, n. 12, p. 48-61, jun. 1985), e de Vinicius Dantas, "A nova poesia brasileira e a poesia" (Novos Estudos. Sāo Paulo: Cebrap, n. 16, dez. 1986).

2 SISCAR, Marcos. A cisma da poesia brasileira. Sibila: Revista de Poesia e Cultura. São Paulo: Ateliê, v. 8-9, p. $41-60,2005$. 
na Coleção Ás de Colete da editora Cosac Naify, é um marco na divulgação de sua obra e na possibilidade de despertar mais estudos. ${ }^{3}$

Os termos com que algumas vezes a crítica tentou abordar a obra de Orides sinalizam a dificuldade para localizá-la em seu momento: desde termos genéricos, como "metafísica", até novas proposições de movimentos: como "neossimbolista". Não se trata de uma poesia confessional, tampouco de referenciais explícitos: ela cria, com limitados elementos, um mundo próprio. ${ }^{4}$ Mas uma abordagem mais detida de seus poemas permite entrever que Orides não está totalmente alheia a algumas tendências contemporâneas ou anteriores a ela.

Embora seu primeiro livro, Transposição, só tenha sido publicado em 1969, pode-se pensar que sua dicção mais sublime tenha recebido o influxo da chamada Geração de 45, que combatia o prosaísmo e o coloquialismo da poesia de 22. Inclusive na parte Antigos de Rosácea, Orides inclui sonetos datados entre 1962 e 1968. Contudo, é justamente sob o velado signo de um poeta que inicialmente foi classificado nesse grupo, logo superando-o, que ela desenvolve sua poética. Principalmente um primeiro Cabral, de "Psicologia da composição" e "Fábula de Anfion", pode ser indicado como um parâmetro para Orides de uma poética concisa, na qual a palavra recobra sua materialidade vista como coisa. A falta de lirismo e paixão cedeu lugar a uma disciplina formal e de autoconhecimento. O silêncio é sempre entrevisto, não como uma ameaça, mas incorporado a sua poética repleta de vazios. Entre os poucos poemas que expressamente esboçam uma poética, encontramos este "Poema", de Alba:

Saber de cor o silêncio

diamante e/ou espelho

o silêncio além

do branco.

Saber seu peso

seu signo

- habitar sua estrela impiedosa.

3 Contém os cinco livros publicados por Orides: Transposição (1969), Helianto (1973), Alba (1983), Rosácea (1986) e Teia (1996).

4 Entre as interpretações, destaca-se o sensivel ensaio de Alcides Villaça, Símbolo e acontecimento na poesia de Orides. Novos Estudos. São Paulo: Cebrap, n. 34, p. 198-214, nov. 1992.

196. CARVALHO, Ricardo Souza de. Albas e antilogias da poesia brasileira contemporânea 
Saber seu centro: vazio

esplendor além

da vida além

da memória.

Saber de cor o silêncio.

- e profaná-lo, dissolvê-lo

em palavras. ${ }^{5}$

Antes de Orides, a poesia concreta já havia escolhido Cabral como um antecessor importante na constituição de uma postura construtivista. Por sua vez, a poeta não se revela indiferente à grande presença do grupo Noigandres de São Paulo. Alguns de seus poemas apresentam um corte e uma disposição próximos das técnicas concretistas; no espaço limitado de seus signos (rosa, pássaro, água, entre outros), eles se repetem, combinam-se, trocam de posição, deslocam-se em função de espaços em branco. Longe de ser uma configuração radical, percebemos essa presença no poema "Vigília", também de Alba:

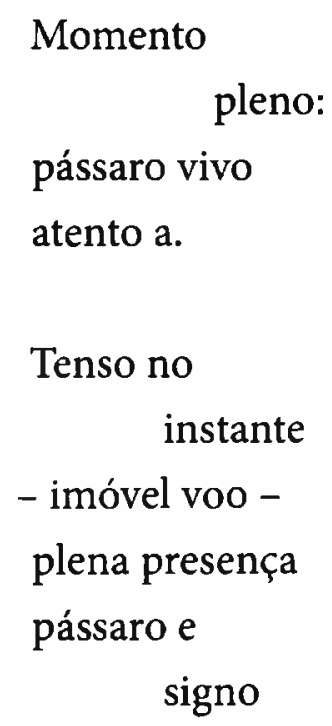


(atenção branca

aberta e

vívida).

Pássaro imóvel.

Pássaro vivo

atento

a. ${ }^{6}$

No entanto, a apropriação de técnicas concretistas não se dá apenas em função da autoconsciência da linguagem e da configuração de uma modernidade, mas, antes de mais nada, em relação a signos naturais e atemporais.

Orides também não passa incólume à avalanche da "poesia marginal", aberta ao mais prosaico da vida cotidiana, plasmado na linguagem mais direta possível. Porém, já distante dos modismos, experimenta em Rosácea uma renovação na perspectiva, segundo ela própria, de "abandonar o sublime, assumir o pessoal e concreto, condensar as abstrações como imagens"' Assim como observamos quanto à poesia concreta, aqui também não se trata de uma participação ativa em um novo movimento poético. Ao mesmo tempo em que segue uma coerência interna ao longo de sua obra, atualiza-se em relação a todo um contexto que deseja retirar os mitos ainda existentes da poesia como algo sublime, a "poesia dita profunda" nos termos de Cabral. No entanto, mesmo quando ela se permite confessar, falar de sua história de vida, reduz ao máximo o seu repertório de signos, como no poema "Herança":

Da avó materna:

uma toalha (de batismo).

Do pai:

um martelo

um alicate

uma torquês

duas flautas.

6 Idem, p. 150.

7 Depoimento recolhido em MASSI, Augusto (org.). Artes e oficios da poesia. Porto Alegre: Artes e Ofícios, 1991, p. 261. 
Da mãe:

um pilão

um caldeirão

um lenço. ${ }^{8}$

A relação de objetos prosaicos, destacados tanto no sentido de coisas, quanto de signos poéticos, diz muito mais do que sua aparente escassez parece indicar em um primeiro momento. A origem humilde reparte-se na divisão social e cultural dos gêneros: as mulheres da família oferecem aquilo que está ligado ao ambiente doméstico e mais reservado; já o homem deixa seus instrumentos manuais de trabalho, mas com uma abertura ao ócio, à diversão, pela ocorrência das "duas flautas". Ainda em Rosácea, a parte "Lúdicos" finalmente poderia denunciar que Orides teria se rendido aos encantos de uma musa em tom menor, menos sisuda. Disposta a experimentar, ela se permite ser um pouco diferente, ousar outro registro poético. Apesar da inegável leveza que perpassa esses versos, eles ainda concentram a profundidade da percepção da poeta. Assim mesmo, chama a atenção uma série de poemas dedicados a Drummond, sugestivamente indicados pelas iniciais CDA: a provocação irônica, mais do que revelar a dívida para com o mestre, sugere que a proposta modernista perde em intensidade nos dias de hoje.

\section{CDA (imitado)}

O vida, triste vida!

Se eu me chamasse Aparecida

dava na mesma. ${ }^{9}$

A glosa se dá a partir do célebre "Poema de sete faces" que abre a primeira coletânea drummondiana, Alguma poesia (1930), que não custa ser lembrado: "Mundo mundo vasto mundo,/ se eu me chamasse Raimundo/ seria uma rima, não seria uma solução.". Para quem, entre outros temores, fugia do rótulo de "poesia feminina",

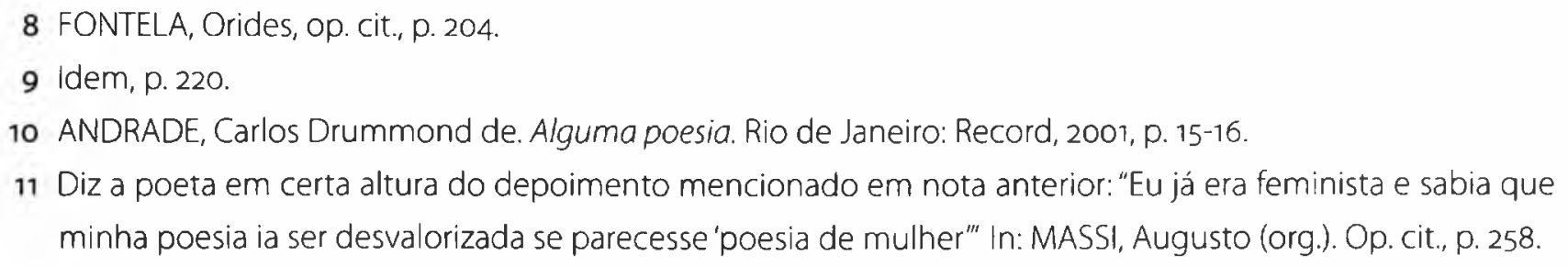


retomar o dilema do poema modernista deslocando-o para um nome de mulher sinaliza que, no final das contas, determinações históricas, sociais ou de gênero, pouco importariam na hora de fazer poesia. Resposta curta e grossa aos prováveis críticos que a acusassem de uma poesia abstrata e sem compromissos.

Já Sebastiāo Uchoa Leite abriu-se mais do que Orides Fontela, tanto no que se refere à participação no meio literário, quanto à divulgação de sua obra. Em comum, aproveitou algumas lições das experiências que passavam a sua porta, mas sem dogmatismos nem restrições.

Se começou pelos últimos resquícios do período classicizante da poesia brasileira a saber, seus Dez sonetos sem matéria (1958-1959) -, foi pela obra de seu conterrâneo João Cabral que realmente encontrou a medida de uma poesia consciente de sua própria linguagem:

João era um poeta que nos influenciava muito aqui porque era um poeta pernambucano que tinha sobressaído nacionalmente com uma obra curiosamente voltada para a localidade [...]. O elemento da construtividade explícito na minha poesia é talvez o que me ligue mais ao João Cabral.'2

Mais uma vez se confirma a poesia cabralina como pedra de toque da produção contemporânea, seja na ratificação de pressupostos, como para os concretistas, seja na recusa a uma poesia cerebral, como para os poetas marginais.

Dessa forma, não é de se estranhar que Uchoa Leite se impressionasse com a proposta da poesia concreta, e passasse a praticar alguns de seus recursos. Porém, longe de ser um fervoroso adepto, aprendeu o que lhe era mais conveniente: a boa lição da leitura constante da tradição poética, não só brasileira, como internacional, e a renovação das formas. Por isso, não se fixou nas lógicas montagens concretistas, caminhando para um poema cada vez mais fragmentário, como uma espécie de nota, esboço. Isso condiz a uma crítica da poesia como espaço apenas de verdades ideais ou veleidades formais. Até mesmo um poema é intitulado "Esboço", e o seguinte, do livro Cortes/Toques (1983-1988), insiste em se apresentar como "Outro esboço":

12 Entrevista de Uchoa Leite a Daniel Augusto. Inimigo Rumor. São Paulo, Rio de Janeiro: Cosac Naify, 7 Letras, n. 16, p. 94-102, $1^{\circ}$ semestre de 2004. Depoimento importante também se encontra em Artes e oficios da poesia, op. cit., p. 308-312.

200 - CARVALHO, Ricardo Souza de. Albas e antilogias da poesia brasileira contemporânea 
A serpente semântica disse:

Não adianta querer

Significar-me

Neste silvo.

Meu único modo de ser é a in

Sinuosidade e a in

Sinuação.

Não é possível pensar

A verdade

Exceto como veneno. ${ }^{13}$

E é contra significados e princípios prévios, estabelecidos, que a poesia de Uchoa Leite vai insurgir-se. O poeta também se posiciona em relação aos embates de seu tempo, mas sem compartilhar com os maniqueísmos que muitas vezes permearam uma poesia mais comprometida nos anos 1960 e 1970. Ao contrário, chega a ironizar os discursos "pseudo" politizados, invalidando-os como no poema "História e consciência de classe", da obra Isso não é aquilo (1979-1982):

prazer em conhecê-lo sr. Leite
o senhor
é da classe dominante?
não: sou apenas
uma barata sem antenas
que ignora as taxas de risco
e o índice dow Jones
enfim
um morcego de botequim
sem radar
que marcou bobeira
na maxidesvalorização cambial. ${ }^{14}$

13 LEITE, Sebastião Uchoa. Obra em dobras (1960-1988). São Paulo: Duas Cidades, 1988, p. 20. Depois dessa reuniăo dos seis primeiros livros, o poeta publicou A uma incógnita (1991), A ficção vida (1993), A espreita (2000) e A regra secreta (2002).

14 Idem, p. 85. 
No lugar do vazio dos discursos poéticos e políticos que circulam, Uchoa Leite investe em outros meios de expressão já enraizados na cultura contemporânea, como o jornal, o cinema, as histórias em quadrinhos. Em diálogo com os poetas marginais, esse veio de citação ou alusão aos meios de comunicação em massa torna-se matéria-prima não apenas para a poesia, mas para diversas manifestações literárias e artísticas. A nota humorística desnuda o objeto referenciado, atribuindo-lhe um novo sentido, como nessa "Alice despida por seus ilustradores (de um desenho de Ismael Caldas)":

De bruços
a cabeça inclinada no braço
o laço vitoriano solto
a barra do vestido erguida
as botinhas cruzadas:
o olho bate
e só vê a calcinha
que mr. Dodgson nunca viu. ${ }^{15}$

As obras que a personagem de Lewis Carrol protagoniza - Aventuras de Alice no país das maravilhas e Alice através do espelho e o que Alice encontrou lá - foram traduzidas por Uchoa Leite ${ }^{16}$, que não só se interessava pelos jogos de linguagem do autor inglês, como também pela visualidade despertada em torno à obra dele. $\mathrm{O}$ poema acima interage com o belo ensaio "O universo visual de Lewis Carrol"17, no qual Uchoa Leite se detém nos ilustradores de Alice e na fotografia de Carrol. Assim, cria-se uma rede formada por poesia e ensaio que explicita a fascinação do poeta pelo signo visual.

Diferentemente da menção explícita a poetas modernistas que Orides e outros fazem em seus poemas, Uchoa Leite decide ampliar o sentido de tradição poética. Nesse ponto, ele não segue a historiografia literária mais corrente - que por sua vez

15 Idem. Isso não é aquilo, p. 74.

16 Aventuras de Alice no país das maravilhas e Alice através do espelho e o que Alice encontrou lá. ga edição. São Paulo: Summus Editorial, 1980

17 Crítica de ouvido. São Paulo: Cosac Naify, 2003, p. 115-142. Esse texto figura na parte sugestivamente intitulada "Imagem e linguagem", que também contém "As relações duvidosas: notas sobre literatura e cinema", outra presença marcante na obra de Uchoa Leite. 
parece ser a também seguida pelos poetas - de considerar o modernismo como verdadeiro marco zero e desvalorizar as contribuições anteriores. Seguindo o que ele mesmo propõe no título Antilogia (1972-1979), vai contra as antologias tradicionais, nas quais não se encontra um lugar apropriado para poetas como Augusto dos Anjos (1884-1914). No "poemontagem" dedicado ao autor de $E u$, Uchoa Leite funde as imagens mórbidas do homenageado com uma dicção de vanguarda, numa espécie de tradução para os dias de hoje de um poeta que não se enquadrava bem no seu tempo:

[...]

Homem engrenagem da língua paralítica

No orbe oval de gosmas amarelas

Eu perdido no cosmos corpo inerme

De mim diverso um coveiro do verso. ${ }^{18}$

Felizmente as trajetórias de Orides Fontela e Sebastião Uchoa Leite não são únicas, podendo ser acrescentadas as de outros nomes que a crítica vem reconhecendo como importantes no cenário da poesia contemporânea. Para os dois poetas falecidos recentemente, com o conjunto da obra já fechado, deve-se iniciar uma leitura que leve em consideração, ao lado de suas dívidas para com as vertentes poéticas do século $\mathrm{xx}$, o legado para os novos poetas de uma postura aberta e crítica aos repertórios que nos cercam.

Ricardo Souza de Carvalho é professor de Literatura Brasileira na Universidade de São Paulo, autor de A Espanha de João Cabral e Murilo Mendes (Editora 34, no prelo).

18 LEITE, Sebastião Uchoa, op. cit., p. 118. Também Cabral reabilitou Augusto dos Anjos em poema da série "O sim contra sim", de Serial (1959-1961). 